\title{
MEMAHAMI KEDUDUKAN DAN KAPASITAS HUKUM ADAT DALAM POLITIK PEMBANGUNAN HUKUM NASIONAL
}

\author{
I Nyoman Nurjaya \\ Guru Besar Fakultas Hukum Universitas Brawijaya Malang \\ e-mail: nurjayai@yahoo.com
}

\begin{abstract}
ABSTRAK
Indonesia telah dikenal sebagai negara yang memiliki keragaman budaya, tercermin dari kekayaan budaya yang meliputi kebhinnekaan suku bangsa, agama, bahasa, dan juga keragaman stratifikasi kehidupan sosial masyarakatnya. Motto Bhinneka Tunggal Ika merupakan refleksi empirik dari keragaman kehidupan sosial dan budaya yang membentuk identitas bangsa Indonesia. Hukum adat adalah salah satu dari produk budaya bangsa Indonesia, khususnya kebudayaan idiil, yang membentuk identitas hukum asli masyarakat Indonesia. Dalam kaitan dengan kebijakan pembangunan hukum nasional semestinya hukum adat menjadi referensi yang patut diperhitungkan untuk memperkaya substansi hukum nasional, karena fakta kemajemukan hukum dalam masyarakat adalah keniscayaan yang tidak dapat dipungkiri dalam dalam kehidupan hukum di Indonesia. Artikel ini mencoba untuk memberi pemahaman yang lebih holistik mengenai kedudukan dan kapasitas hukum dalam kebijakan pembangunan hukum nasional dalam negara dan bangsa yang bercorak kemajemukan budaya.
\end{abstract}

Kata Kunci: keragaman budaya, kedudukan dan kapasitas hukum adat, kebijakan pembangunan hukum nasional.

\begin{abstract}
Indonesia has been well known as a multicultural country in Southeast Asia region in term of its ethnic, religion, racial and social stratification. It is, therefore, Unity in Diversity is reflected as an official motto of the State in order to describe the empirical social and cultural diversity of Indonesia. The diversity refers to a cultural configuration which reflect the Nation identity of Indonesia, forming elements of cultural capital as well as cultural power that generate the life of Nation State of Indonesia. In the effort of National Law development then questioned whether the existence of adat law as living law and product of culture can be accounted as instrument for enriching substance of National Law? The article attempts to offer answer of the above fundamental question by employing legal anthropology approach with the purpose of obtaining a better understanding holistically regarding the development of National law in multicultural country toward a more just and equitable of State law of Indonesia in particular.
\end{abstract}

Keywords: unity in diversity, Nation State of Indonesia, adat law, national law development.

\section{PENDAHULUAN}

Indonesia dikenal sebagai negara yang bercorak multikultural, multietnik, agama, ras, dan multi golongan. Sesanti Bhinneka Tunggal Ika secara de facto mencerminkan kemajemukan budaya bangsa dalam naungan Negara Kesatuan Republik Indonesia. Wilayah negara yang membentang luas dari Sabang sampai Merauke. Indonesia memiliki sumber daya alam (natural resources) yang kaya dan melimpah bak untaian zamrud mutu manikam di bentang garis katulistiwa, dan berwujud sebagai sumber daya budaya (cultural resources) yang beragam coraknya (Koentjaraningrat, 1988; Hardjono, 1991).
Dari satu sisi, secara teoritis keragaman budaya (multikultural) merupakan konfigurasi budaya (cultural configuration) yang mencerminkan jatidiri bangsa, dan secara empirik menjadi unsur pembentuk Negara Kesatuan Republik Indonesia (NKRI). Selain itu, kemajemukan budaya juga menjadi modal budaya (cultural capital) dan kekuatan budaya (cultural power) yang menggerakkan dinamika kehidupan berbangsa dan bernegara (Dhari dan Suparman, 1999). Namun demikian, dari sisi yang lain kemajemukan budaya juga menyimpan potensi konflik yang dapat mengancam integrasi bangsa, karena konflik antar budaya dalam wujud pertikaian antar etnik, 
antar penganut agama, ras maupun antar golongan bersifat sangat sensitif dan rentan terhadap suatu kondisi yang menjurus ke disintegrasi bangsa. Hal ini sangat mungkin terjadi apabila konflik tersebut tidak dikelola, dimaknai, dan diselesaikan secara santun, damai, dan bijaksana oleh pemerintah bersama seluruh komponen anak bangsa.

Dari perspektif antropologi, konflik merupakan fenomena sosial yang tak terpisahkan (inherent) dari kehidupan manusia, apalagi dalam masyarakat bercorak multikultural. Ia tidak mungkin dihindari atau diabaikan dalam kehidupan bersama. Yang harus dilakukan adalah bagaimana konflik itu dikelola, dikendalikan, diakomodasi, dan diselesaikan secara damai dan bijaksana agar tidak menimbulkan disintegrasi sosial dalam kehidupan masyarakat (Bohanan, 1967; Spradley \& McCurdy, 1987).

Dalam kurun waktu empat dasawarsa terakhir ini, kasus-kasus konflik yang bersumber dari potensi kemajemukan budaya cenderung semakin meningkat kualitas maupun kuantitasnya. Konflik-konflik dalam kehidupan masyarakat di Aceh, Abepura dan Timika (Papua), Ambon (Maluku), Ternate (Maluku Utara), Sampit-Sambas (Kalimantan Tengah), PasuruanSitubondo (Jawa Timur), DKI Jakarta, Mataram (Nusa Tenggara Barat), Lampung, Poso (Sulawesi Tengah), Pontianak (Kalimantan Barat), dan lainlain merupakan cerminan dari sensitifitas dari potensi keragaman budaya menimbulkan konflik dan pertikaian antar etnik, antar komunitas agama, dan/atau antar golongan yang terjadi di berbagai kawasan Indonesia.

Dari perspektif antropologi hukum, fenomena konflik muncul karena adanya konflik nilai (conflict of value), konflik norma (conflict of norm), dan/atau konflik kepentingan (conflict of interest) dari komunitas etnik, agama, maupun golongan termasuk juga komunitas politik dalam masyarakat. Selain itu, dapat dicermati bahwa konflik yang terjadi dalam masyarakat juga bersumber dari persoalan diskriminasi pengaturan dan perlakuan pemerintah pusat terhadap komunitas-komunitas masyarakat di daerah, dengan menggunakan istilah yang disebut Bodley (1982) sebagai politik pengabaian (political of ignorance), sebagai perlakuan yang mengabaikan, menggusur, dan bahkan mematisurikan nilai-nilai, norma-norma hukum rakyat (folk law), termasuk religi dan dan tradisi-tradisi masyarakat di daerah melalui dominasi hukum negara (state law) yang bercorak sentralisme hukum (legal centralism).

Secara konvensional cita hukum (idea of law atau rechts idee) sebagaimana dikemukakan Gustav
Radbruch adalah untuk menciptakan keadilan (gerechtmatigheid atau justice), kemanfaatan (doelmatigheid atau utilitity), dan kepastian hukum (rechtmatigheid atau legal certainty). Sedangkan tujuan dari hukum adalah untuk menjaga keteraturan (social order) dan ketertiban sosial (legal order) dalam masyarakat, sehingga fungsi hukum lebih ditekankan sebagai instrumen pengawasan sosial (social control).

Dalam masyarakat yang lebih kompleks, cita hukum dikembangkan sebagai alat untuk merekayasa kehidupan sosial (social engineering). Apakah cita hukum dalam masyarakat multikultural hanya terbatas pada kedua tujuan di atas? Apakah cita hukum dapat ditingkatkan agar memainkan peran sebagai instrumen untuk memelihara dan memperkokoh integrasi bangsa dalam masyarakat yang bercorak multikultural? dan bagaimana kedudukan dan kapasitas hukum adat dalam politik pembangunan hukum nasional di negeri ini? Uraian berikut ini mencoba untuk memberi jawaban atas ketiga pertanyaan fundamental di atas, dengan menggunakan pendekatan antropologi hukum (legal anthropology) sebagai bagian dari kajian hukum empirik (empirical study of law).

\section{PEMBAHASAN}

\section{Hukum dalam Perspektif Antropologi: Posisi Hukum Rakyat dalam Sistem Hukum Negara}

Studi tentang hukum sebagai sistem pengendalian sosial (social control) dalam kehidupan masyarakat telah banyak dilakukan oleh para ahli antropologi (Black, 1976, 1984). Karena itu, dikatakan bahwa para antropolog memberi kontribusi yang sangat bermakna dalam pengembangan konsep hukum yang dioperasikan dalam masyarakat (Griffiths, 1986:2).

Anthropologist have focused upon micro processes of legal action and interaction, they have made the universal fact of legal pluralism a central element in the understanding of the working of law in society.

Para ahli antropologi mempelajari hukum bukan hanya sebagai produk dari hasil abstraksi logika sekelompok orang yang memiliki otoritas yang diformulasikan dalam bentuk peraturan, tetapi lebih mempelajari hukum sebagai perilaku sosial (Llewellyn dan Hoebel, 1941; Hoebel, 1954; Black \& Mileski, 1973; Moore, 1978; Cotterrel, 1995). Hukum dipelajari sebagai bagian integral dari kebudayaan secara keseluruhan, dan hukum dipelajari sebagai produk dari interaksi sosial yang dipengaruhi oleh aspek kebudayaan yang lain, seperti politik, ekonomi, religi, dan lain-lain (Pospisil, 1971); atau hukum dipelajari sebagai proses sosial yang berlangsung dalam kehidupan masyarakat (Moore, 1978). 
Hukum dalam perspektif antropologi bukan semata-mata hanya berwujud peraturan perundangundangan yang diciptakan oleh negara (state law), tetapi juga hukum dalam wujudnya sebagai peraturan-peraturan lokal yang bersumber dari suatu kebiasaan masyarakat (customary law), termasuk pula mekanisme-mekanisme pengaturan sendiri (self-regulation atau inner-order mechanism) yang juga berfungsi sebagai sarana pengendalian sosial (legal order) dalam masyarakat. Dengan demikian, studi-studi antropologis mengenai hukum, dikenal sebagai antropologi hukum (legal anthropology atau anthropological study of law), pada dasarnya mempelajari hubungan timbal-balik antara hukum dengan fenomena-fenomena sosial yang berlangsung dalam kehidupan masyarakat; bagaimana hukum mempunyai fungsi dalam kehidupan masyarakat, atau bagaimana hukum bekerja sebagai alat pengendalian sosial dalam masyarakat.

Studi antropologis mengenai hukum memberi perhatian pada segi kebudayaan manusia yang berkaitan dengan fenomena hukum dalam fungsinya sebagai sarana menjaga keteraturan sosial (social order) (Pospisil, 1971, 1973; Ihromi, 1989). Maka, antropologi hukum secara khusus mempelajari proses sosial dalam pengaturan mengenai hak dan kewajiban warga masyarakat diciptakan, dirubah, dimanipulasi, diinterpretasi, dan diimplementasikan oleh warga masyarakat (F. von Benda-Beckmann, 1989).

Dari satu sisi, hukum dalam pengertian yang sempit dipelajari sebagai sistem pengendalian sosial dalam bentuk peraturan perundang-undangan yang dibuat oleh pemerintah dalam satu bangunan negara (state law), dan karena itu pranata-pranata hukum seperti polisi, jaksa, pengadilan, penjara dan lain-lain diciptakan sebagai alat negara yang bertugas menjaga ketertiban sosial (social control). Dari perspektif antropologi hukum, produk kebudayaan yang disebut hukum tidak hanya terdapat dalam suatu organisasi masyarakat yang berbentuk negara, tetapi terdapat dalam setiap bentuk komunitas masyarakat. Karena itu, hukum selain terwujud dalam bentuk peraturan perundang-undangan Negara, juga terwujud sebagai mekanisme-mekanisme pengendalian sosial dalam sistem hukum rakyat (folk law-indigenous lawcustomary law) yang dalam konteks Indonesia dikenal sebagai hukum adat (adat law).

Norma-norma hukum yang berlaku di masyarakat secara metodologis dapat dipahami dari keputusankeputusan seseorang atau sekelompok orang yang secara sosial diberi otoritas untuk menjatuhkan sanksi kepada para pelanggar hukum. Karena itu, untuk menginvestigasi hukum yang hidup dalam masyarakat (living law) dapat dilakukan melalui tiga cara, yaitu a. Dengan menginvestigasi normanorma abstrak yang direkam dari ingatan-ingatan para kepala adat, tokoh masyarakat, atau pemegang otoritas yang diberi wewenang membuat keputusankeputusan hukum (ideological method); b. Dengan melakukan pengamatan terhadap setiap tindakan nyata (perilaku) aktual anggota masyarakat dalam kehidupan sehari-hari ketika berinteraksi dalam komunitasnya (descriptive method); c. Dengan mengkaji kasus-kasus sengketa yang pernah atau sedang terjadi dalam masyarakat (trouble-cases method) (Llewellyn \& Hoebel, 1941).

Kasus-kasus sengketa yang dipilih dan dikaji secara seksama adalah cara yang utama untuk dapat memahami hukum yang berlaku dalam masyarakat. Data yang diperoleh dari pengkajian tersebut sangat meyakinkan dan kaya, karena dari kasus-kasus tersebut dapat diungkapkan banyak keterangan mengenai norma-norma hukum yang sedang berlaku dalam masyarakat (Hoebel, 1954).

The trouble-cases, sought out and examined with care, are thus the safest main road into the discovery of law. Their data are most certain. Their yield is richest. They are the most revealing.

Kajian kasus sengketa pada intinya ditujukan untuk mengungkapkan latar belakang dari munculnya kasus tersebut, cara yang ditempuh untuk menyelesaikan sengketa, mekanisme penyelesaian sengketa yang digunakan, dan sanksi yang dijatuhkan kepada pihak yang dipersalahkan, sehingga dapat diungkapkan prinsip hukum yang berlaku, prosedur yang ditempuh, dan nilai-nilai budaya yang mendukung proses penyelesaian sengketa tersebut. Sedangkan, materi kasus sengketa yang dapat dikaji untuk memahami hukum yang berlaku dalam masyarakat meliputi: kasus sengketa yang dapat dicermati mulai dari awal sampai sengketa diselesaikan; kasus sengketa yang dapat dikaji melalui dokumen keputusan pemegang otoritas yang diberi wewenang menyelesaikan sengketa; kasus sengketa yang dapat direkam dari ingatan-ingatan para tokoh masyarakat atau para pemegang otoritas; dan kasus sengketa yang masih bersifat hipotetis (Nader dan Todd, 1978).

Kasus-kasus sengketa sangat umum digunakan sebagai metode untuk menelusuri hukum masyarakat dalam studi antropologis mengenai hukum. Hal ini karena hukum bukanlah semata-mata sebagai suatu produk dari individu atau sekelompok orang yang mempunyai otoritas membuat peraturan perundangundangan, atau bukanlah sebagai suatu institusi yang terisolasi dari aspek-aspek kebudayaan yang 
lain, tetapi hukum merupakan produk dari suatu relasi sosial dalam sistem kehidupan masyarakat. Karena itu, hukum muncul sebagai fakta khas yang lebih menekankan empirik, ekspresi, atau perilaku sosial masyarakat, dan penyelesaian kasus sengketa merupakan ekspresi dari hukum yang secara nyata berlaku dalam masyarakat (Llewellyn dan Hoebel, 1941; Hoebel, 1954).

Sampai sekarang pengkajian kasus-kasus sengketa menjadi metode khas dalam studi-studi antropologis tentang hukum dalam masyarakat. Namun demikian, dalam kondisi-kondisi tertentu dimana sangat sulit ditemukan kasus sengketa yang dapat dianalisa dan digeneralisasi sebagai ekspresi dari hukum dalam suatu masyarakat, maka dapat dikaji interaksi-interaksi antar individu atau kelompok dalam masyarakat yang tanpa diwarnai dengan sengketa.

Perilaku-perilaku warga masyarakat yang tanpa diwarnai dengan sengketa juga menjadi media sosial untuk menginvestigasi norma-norma hukum dalam masyarakat. Perilaku warga masyarakat dalam kehidupan sehari-hari yang berlangsung secara normal tanpa ada sengketa juga dapat menjelaskan prinsipprinsip hukum yang terkandung di balik perilakuperilaku tersebut. Praktik-praktik kehidupan warga masyarakat dalam peristiwa-peristiwa khusus yang memperlihatkan ketaatan secara sukarela terhadap norma-norma sosial sesungguhnya merupakan kasus-kasus konkrit yang tidak diwarnai dengan sengketa.

Perilaku-perilaku warga masyarakat yang memperlihatkan ketaatan terhadap pengaturan-pengaturan sosial, apabila diobservasi dan dicermati secara seksama merupakan unit-unit analisa yang dapat digunakan untuk menjelaskan prinsip-prinsip dan norma-norma hukum yang mengatur perilaku warga masyarakat. Cara penelusuran prinsip-prisip dan norma-norma pengaturan sosial seperti dimaksud di atas disebut Holleman (1986) sebagai metode kajian kasus tanpa sengketa (trouble-less case method).

Selain mengkaji kasus-kasus sengketa dalam masyarakat, antropologi hukum juga memberi perhatian pada fenomena kemajemukan hukum (legal pluralism) dalam masyarakat (Cotterrell, 1995:306).

We should think of law as a social phenomenon pluralistically, as regulation of many kinds existing in a variety of relationships, some of the quite tenuous, with the primary legal institutions of the centralized state. Legal anthropology has almost always worked with pluralist conceptions of law.

Dari perspektif antropologi hukum dapat dijelaskan bahwa hukum yang secara nyata berlaku dalam masyarakat selain terwujud dalam bentuk hukum negara (state law), juga terwujud sebagai hukum agama (religious law), hukum kebiasaan (customary law). Selain itu, hukum juga dapat terwujud dalam mekanisme pengaturan lokal (inner order mechanism atau self-regulation) yang secara nyata berlaku dan berfungsi sebagai sarana pengendalian sosial (social control) dalam masyarakat (F. von Benda-Beckmann, 1989; Snyder, 1981; Griffiths, 1986; Hooker, 1987; K. von Benda-Beckmann \& Strijbosch, 1986; Moore, 1986; Spiertz \& Wiber, 1998).

Ini berarti bahwa hukum negara (state law) bukan merupakan satu-satunya wujud hukum yang berlaku dalam masyarakat. Jika hukum diartikan sebagai instrumen kebudayaan yang berfungsi untuk menjaga keteraturan sosial (social order), atau sebagai sarana pengendalian sosial (social control), maka selain hukum negara juga terdapat sistem-sistem hukum lain seperti hukum rakyat (folk law-customary law-adat law), hukum agama (religious law), dan juga mekanisme-mekanisme pengaturan sendiri (self-regulation atau inner-order machanism) dalam masyarakat. Inilah yang disebut sebagai fakta kemajemukan hukum (legal pluralism) dalam kajian antropologi hukum.

Fakta kemajemukan hukum (legal pluralism) secara umum digunakan untuk menjelaskan suatu situasi dimana dua atau lebih sistem hukum berlaku secara berdampingan dalam satu bidang kehidupan sosial (social field); atau untuk menjelaskan keberadaan dua atau lebih sistem pengendalian sosial dalam yang berlaku dalam masyarakat (Griffiths, 1986); atau menerangkan suatu situasi dimana dua atau lebih sistem hukum berinteraksi dalam satu kehidupan sosial (Hooker, 1975), atau suatu kondisi dimana lebih dari satu sistem hukum bekerja secara berdampingan dalam aktifitas dan hubungan dalam masyarakat (F. von Benda-Beckmann, 1999).

Ajaran mengenai pluralisme hukum (legal pluralism) secara umum dipertentangkan dengan ideologi sentralisme hukum (legal centralism). Ideologi sentralisme hukum diartikan sebagai suatu ideologi yang menghendaki pemberlakuan hukum negara (state law) sebagai satu-satunya hukum bagi semua warga masyarakat, dengan mengabaikan keberadaan sistem-sistem hukum yang lain, seperti hukum agama (religious law), hukum kebiasaan (customary law), dan juga semua bentuk mekanismemekanisme pengaturan lokal (self-regulation) dalam masyarakat. Dalam konteks ini, Griffiths (1986:12) menegaskan:

The ideology of legal centralism, law is and should be the law of the state, uniform for all persons, exclusive of all other 
law, and administered by a single set of state institutions. They ought to be and in fact are hierarchically subordinate to the law and institutions of the state.

Dengan demikian, ideologi sentralisme hukum cenderung mengabaikan kemajemukan sosial dan budaya dalam masyarakat, termasuk norma-norma hukum rakyat (folk law) yang secara nyata dianut dan bahkan lebih ditaati warga masyarakat dari pada hukum yang diciptakan dan diberlakukan oleh negara (state law). Karena itu, pemberlakuan ideologi sentralisme hukum dalam suatu komunitas yang bersifat multikultural hanya merupakan sebuah utopia. Dalam hubungan ini, Griffiths (1986:4) menyatakan:

Legal pluralism is the fact. Legal centralism is a myth, an ideal, a claim, an illusion. Legal pluralism is the name of a social state of affairs and it is a characteristic which can be predicted of a social group.

Uraian di atas memperlihatkan bahwa basis hukum berada dalam masyarakat itu sendiri, sehingga untuk memahami hukum dalam masyarakat secara utuh maka hukum harus dipelajari sebagai bagian yang tak terpisahkan dengan aspek-aspek kebudayaan yang lain, seperti sistem politik, sistem ekonomi, organisasi atau struktur sosial, sistem kekerabatan, sistem religi, dan lain-lain (Hoebel, 1954:5).

We must have a look at society and culture at large in order to find the place of law within the total structure. We must have some idea of how society works before we can have a full conception of what law is and how it works.

Hukum sebagai suatu sistem (legal system) dipelajari sebagai produk budaya yang pada pokoknya mempunyai tiga elemen, yaitu: a. Struktur hukum (legal structure) meliputi lembaga legislatif dan institusi penegak hukum (polisi, kejaksaan, pengadilan, dan lembaga pemasyarakatan); b. Substansi hukum (legal substance) meliputi semua produk hukum berupa peraturan perundang-undangan; dan c. Budaya hukum masyarakat (legal culture) meliputi nilai-nilai, ide, persepsi, pendapat, sikap, keyakinan, dan perilaku, termasuk harapan-harapan masyarakat terhadap hukum (Friedman, 1975).

Dalam perspektif antropologi hukum setiap bentuk masyarakat memiliki struktur hukum, substansi hukum, dan budaya hukum sendiri. Apakah substansi dan struktur hukum ditaati atau sebaliknya, atau hukum dapat berlaku secara efektif atau tidak akan sangat tergantung pada kebiasaan (custom), tradisi (tradition), atau budaya hukum (legal culture) masyarakat yang bersangkutan. Melalui kajian hukum sebagai suatu sistem (law as a system) dapat dijelaskan bagaimanakah hukum bekerja dalam masyarakat, atau bagaimana sistem-sistem hukum dalam konteks pluralisme hukum saling berinteraksi dalam suatu bidang kehidupan sosial (social field) tertentu. Dari ketiga sub sistem dalam hukum tersebut, kultur hukum (legal culture) menjadi bagian dari kekuatan sosial yang menentukan efektifitas hukum dalam masyarakat; kultur hukum menjadi motor penggerak yang memberi masukan kepada unsur struktur hukum dan substansi hukum dalam memperkuat sistem hukum. Jadi, dengan mengkaji substansi, struktur, dan budaya hukum sebagai satu kesatuan yang tak terpisahkan satu sama lain, maka dapat dipahami suatu situasi bagaimana hukum beroperasi sebagai suatu sistem dalam masyarakat (Friedman, 1984).

\section{Hukum Adat dalam Politik Pembangunan Hukum Nasional}

Uraian pada bagian terdahulu memperlihatkan bahwa hukum dalam perspektif antropologi dipelajari sebagai sistem pengendalian sosial (social control) menjaga keteraturan dalam kehidupan sosial (social order) (Black, 1984).

Anthropologist have similarly concentrated on what they regards as law - typically the most formal and dramatic aspects of social control in tribal and other simple societies - although this often includes nongovernmental as well as governmental process.

Hukum dalam fungsinya sebagai alat pengendalian sosial merupakan salah satu peran dari hukum (law as a tool of social control) dalam masyarakat (Black, 1973). Seiring dengan tuntutan perkembangan masyarakat itu sendiri, terutama dalam masyarakat yang semakin kompleks, peran hukum kemudian diarahkan dan ditingkat sebagai sarana untuk melakukan rekayasa kehidupan sosial (law as a tool of social engineering), atau untuk melakukan perubahan-perubahan sosial dengan menggunakan instrumen hukum (social engineering by law) untuk mencapai kondisi sosial yang dikehendaki oleh Negara yang direpresentasikan oleh pemerintah (Moore, 1978; Rahardjo, 1982; Darmodiharjo \& Shidarta, 1996).

Hukum juga berfungsi sebagai media fasilitasi interaksi antar manusia (law as facilitation of human interaction), untuk mencapai keteraturan dalam kehidupan sosial (social order). Dalam wacana ilmu hukum dijelaskan bahwa cita dari hukum pada dasarnya dimaksudkan untuk mencapai tiga tujuan sekaligus, yaitu: mencapai keadilan (gerechmatigheid), kemanfaatan (doelmatigheid), dan kepastian hukum (rechtmatigheid) dalam kehidupan bersama (Radbruch, 1961). Karena itu, dalam teori hukum dinyatakan bahwa kaidah hukum memiliki daya berlaku secara filosofis, dalam arti 
sesuai dengan cita-cita hukum yang mencerminkan nilai keadilan dalam masyarakat; berdaya laku secara sosiologis, dalam arti diterima dan diakui sebagai norma yang sesuai dengan nilai-nilai yang hidup dalam masyarakat; dan berdaya laku secara yuridis, dalam arti mempunyai landasan hukum menurut hirarkhi perundang-undangan.

Kaidah hukum pada dasarnya memiliki dua sifat pokok, yaitu bersifat mengatur (regelen/anvullen recht) dan bersifat memaksa (dwingen recht). Yang diatur oleh kaidah hukum adalah perilaku masyarakat untuk menciptakan suasana keteraturan, ketertiban, ketentraman, dan kedamaian (order and peace) dalam kehidupan bersama. Sedangkan, sifat memaksa suatu kaidah hukum tercermin dari penerapan sanksi-sanksi secara represif dari aparat penegak hukum bagi setiap orang yang melanggarnya. Pertanyaan yang muncul kemudian, dapatkah kaidah hukum didayagunakan sebagai instrumen untuk memelihara dan memperkokoh integrasi nasional dalam masyarakat yang bercorak multikultural.

Indonesia adalah negara yang memiliki corak beragam multikultural, termasuk kemajemukan sistem hukum yang berlaku di dalam masyarakat. Hal ini karena selain berlaku sistem hukum negara (state law) secara de facto juga terdapat sistem hukum adat (adat law), hukum agama (religious law), dan juga mekanisme-mekanisme regulasi sendiri (selfregulation) dalam kehidupan masyarakat. Namun demikian, jika dicermati secara seksama maka paradigma pembangunan hukum tersebut yang dianut oleh pemerintah pada kurun waktu lebih dari tiga dasa warsa terakhir ini cenderung memiliki sifat sentralisme hukum (legal centralism), melalui implementasi politik unifikasi dan kodifikasi hukum bagi seluruh rakyat dalam teritori negara (rule-centered paradigm). Implikasinya, hukum negara cenderung menggusur, mengabaikan, dan mendominasi keberadaan sistem-sistem hukum yang lain, karena secara sadar hukum difungsikan sebagai governmental social control (Black, 1976), atau sebagai the servant of repressive power (Nonet \& Selznick, 1978), atau sebagai the command of a sovereign backed by sanction (McCoubrey \& White, 1996).

Ini berarti bahwa dari perspektif antropologi sumber munculnya fenomena konflik tersebut justru dari persoalan paradigma pembangunan hukum (legal development paradigm) yang dianut pemerintah dan lembaga legislatif, yaitu paradigma pembangunan hukum yang bercorak sentralisme hukum (legal centralism). Hal ini kontradiktif dengan fakta kemajemukan hukum dalam masyarakat multikultural. Karena itu, untuk mewujudkan suatu tatanan masyarakat yang terintegrasi secara kultural dalam bangunan sosial yang bernama negara, maka anutan ideologi sentralisme hukum segera harus direformasi dengan anutan paradigma pluralisme hukum (legal pluralism).

Untuk mencapai tujuan ini, salah satu upaya yang harus dilakukan adalah membangun paradigma pembangunan hukum yang memberi pengakuan dan perlindungan secara utuh (genuine recognition) terhadap sistem hukum selain hukum negara, seperti hukum adat (adat law), hukum agama (religious law), dan mekanisme-mekanisme pengaturan lokal (innerorder mechanism) yang secara nyata tumbuh dan berkembang dalam masyarakat. Implikasinya, nilainilai, prinsip-prinsip hukum, institusi, dan tradisi folk law wajib diakomodasi dan diintegrasikan ke dalam sistem hukum nasional, dan dituangkan secara konkrit ke dalam norma hukum negara (peraturan perundangundangan). Ini berarti, karakteristik hukum yang harus dikembangkan untuk membina dan memperkokoh integrasi bangsa yang multikultural adalah hukum yang bercorak responsif (responsive law), yaitu hukum yang merespons dan mengakomodasi nilai, asas, norma, institusi, dan tradisi yang tumbuh dan berkembang secara empirik dalam kehidupan masyarakat (Nonet \& Selznick, 1978:113).

Uraian pada bagian-bagian terdahulu memperlihatkan bahwa hukum dalam perspektif antropologi merupakan aktifitas kebudayaan yang berfungsi selain sebagai instrumen untuk menjaga keteraturan sosial (social order), sarana pengendalian sosial (social control), juga sebagai alat untuk melakukan rekayasa sosial (social engineering) dalam masyarakat (Black \& Milesky, 1973; Black, 1984). Dalam konteks ini, hukum dipelajari sebagai bagian yang integral dari kebudayaan secara keseluruhan, bukan sebagai institusi sosial yang bersifat otonom atau terpisah dari aspek-aspek kebudayaan yang lain, seperti politik, ideologi, ekonomi, religi, struktur sosial, organisasi sosial, dan lain-lain. (Pospisil, 1971). Karena itu, untuk memahami posisi dan kapasitas hukum dalam struktur masyarakat, maka pertamatama harus dipahami kehidupan sosial dan budaya masyarakat tersebut secara utuh (Hoebel, 1954).

\section{PENUTUP \\ Kesimpulan}

Untuk memperoleh pemahaman yang utuh mengenai fungsi dan peran hukum dalam kehidupan masyarakat yang bercorak multikultural, maka 
persoalan politik pembangunan hukum yang dianut pemerintah juga menjadi bagian yang harus dipelajari keterkaitannya secara komprehensif. Secara de facto selama kurun waktu lebih dari tiga dasawarsa terakhir ini, pemerintah cenderung menganut politik pembangunan hukum yang diorientasikan ke arah ideologi sentralisme hukum (legal centralism), sehingga produk hukum nasional cenderung mengabaikan, menggusur, dan bahkan mematisurikan sistem-sistem regulasi selain hukum negara (state law) yang secara empirik tumbuh dan berkembang dalam masyarakat. Fenomena seperti ini di atas dikenal sebagai politik pengabaian kemajemukan hukum (political of legal pluralism ignorance) dalam pembangunan hukum nasional.

\section{Rekomendasi}

Dari perspektif antropologi hukum, fenomena kemajemukan hukum (legal pluralism) merupakan fakta kehidupan hukum dalam masyarakat multikultural. Karena itu, dalam rangka meningkatkan tujuan, fungsi, dan peran hukum dalam masyarakat multikultural, memelihara dan mengukuhkan integrasi bangsa di masa depan, maka harus mulai dilakukan upaya untuk mereformasi paradigma pembangunan hukum nasional, dari anutan ideologi sentralisme hukum (legal centralism) ke anutan ideologi pluralisme hukum (legal pluralism), dengan karakteristik hukum yang bercorak responsif terhadap nilai-nilai, prinsip-prinsip, institusi sosial, dan tradisi yang tumbuh, hidup, dan berkembang dalam masyarakat. Dalam konteks Indonesia, hukum adat adalah sistem hukum rakyat (folk law) yang secara empirik tumbuh dan berkembang dalam kehidupan masyarakat, sebagai sistem norma dan regulasi yang berfungsi sebagai instrumen pengendalian sosial (legal order) yang menjaga keteraturan sosial (social order) dalam masyarakat. Karena itu, hukum tidak hanya terwujud sebagai hukum negara (state law), yang diformulasi dalam peraturan perundangundangan, tetapi juga terwujud dalam hukum agama (religious law), hukum adat (adat law), dan juga dalam mekanisme-mekanisme regulasi internal dalam masyarakat.

\section{DAFTAR PUSTAKA}

\section{Buku:}

Benda-Beckmann, F. Von., 1989, "From The Law of Primitive Man to Social-Legal Study of Complex Societies", dalam Antropologi Indonesia, Majalah Antropologi Sosial dan Budaya No. 47 Tahun XIII, Jakarta: FISIP UI.
Benda-Beckmann, K. Von. and F. Strijbosch (Eds), 1986, Anthropology of Law in The Netherlands, Essays on Legal Pluralism, Dordrecht-Holland: Foris Publications,.

Black, Donald, 1976, The Behavior of Law, New York: Academic Press.

Black, Donald, 1984, Toward a General Theory of Social Control, New York: Academic Press.

Black, Donald dan Maureen Mileski (Eds), 1973, The Social Organization of Law, New York: Seminar Press.

Bodley, John H., 1982, Victims of Progress, California: Mayfield Publishing Company.

Bohannan, Paul (Ed), 1967, Law and Warfare, Studies in the Anthropology of Conflict, Austin and London: University of Texas Press.

Cotterel, Roger, 1995, Law's Community, Legal Theory in Sociological Perspective, Oxford: Clarendo Press.

Darmodiharjo, Darji dan Shidarta, 1996, Pokokpokok Filsafat Hukum, Apa dan Bagaimana Filsafat Hukum Indonesia, Jakarta: Gramedia Pustaka Utama.

Friedman, Lawrence M., 1984, The Legal System, New York: W.W. Norton \& Company.

Griffiths, John, 1986, "What is Legal Pluralism", dalam Journal of Legal Pluralism and Unofficial Law No. 24/1986, pp. 1-56.

Hart, H.L.A., 1961, The Concept of Law, London: The Clarendon Press.

Hoebel, E. Adamson, 1954, The Law of Primitive Man, A Study in Comparative Legal Dynamics, New York: Atheneum.

Hooker, M.B., 1975, Legal Pluralism: Introduction to Colonial and Neo-Colonial Law, London: Oxford University Press.

Hooker, M.B., 1978, Adat Law in Modern Indonesia, Kuala Lumpur: Oxford University Press.

Llewellyn, K.N. and E.A. Hoebel, 1941, The Cheyenne Way, Conflict and Case Law in Primitive Jurisprudence, University of Oklahoma Press.

McCoubrey, Hilaire dan Nigel D. White, 1996, Textbook on Jurisprudence, London: Blackstone Press Limited.

Moore, Sally F., 1978, Law As Process, An Anthropological Approach, London: Routledge \& Kegan Paul Ltd.

Nader, Laura dan harry F. Tood Jr. (Eds), 1978, The Disputing Process Law in Ten Societies, New York: Columbia University Press.

Nonet, Philippe dan Philip Selznick, 1978, Law and 
Society in Transition, Toward Responsive Law, New York: Harper Colophon Books.

Pospisil, Leopold, 1971, Anthropology of Law, A Comparative Study, New York: Harper \& Row Publishers.
Spradley, James P. dan David W. McCurdy, 1987, Comformity and Conflict, Reading in Cultural Anthropology, Boston and Toronto: Little, Brown and Company. 